\title{
A study of the relationship between high school principals and teachers' multiple-intelligences and strategic thinking skills
}

\author{
Roya Afrassiabi ${ }^{\mathbf{a}^{*}}$ and Masoumeh Mohammadabadi ${ }^{\mathrm{b}}$
}

${ }^{a} P h D$ in Educational Management, Management Department, Bojnurd Islamic Azad University, Bojnurd, Iran ${ }^{b}$ MA in Educational Management, Bojnurd Islamic Azad University, Bojnurd, Iran

\section{H R O N I C L E}

Article history:

Received January 20, 2014

Accepted 25 August 2014

Available online

August 262014

Intelligence

Multiple intelligences

Strategic thinking skills

\section{Introduction}

The appointment of efficient and suited managers has been one of the most important issues for both the governmental and the private organizations and institutions which, has turned into a great challenge in the third millennium. Based on the researches carried out, this challenge has brought about much mess up for many firms. Moreover, there have been large changes in the criteria for selecting new managers where, in addition to specialization, job experience and multiple intelligence levels are considered. On the other hand, equipping the organizations with the instrumental advantage of the $21^{\text {st }}$ century's strategic thinking skills has caused the organizations to call for the managers who enjoy higher individual performance in each type of intelligences (Ghorchian, et al., 2011). More *Corresponding author.

E-mail addresses: royae1352 dr@yahoo.com (R. Afrassiabi)

C 2014 Growing Science Ltd. All rights reserved. doi: $10.5267 /$ j.ms 1.2014 .8 .031 
importantly, in regard with the role education plays in a society, selecting efficient and skillful managers proves very significant. A small lapse and mistake in the appointment of managers may result in great losses of non-materialistic reserves: human resources. Thus, deciding on taking on efficient and well-matched managers with high multiple intelligences has become one of the most important concerns of education because appointing such intelligent managers can solve many educational issues, potentially and practically. To be effective, managers need to have a spectrum of intelligences to employ skills, especially the strategic thinking skills, appropriately.

Of the most recent theories, concerning intelligence is Howard Gardner's multiple intelligence theory (Gardner, 1985, 1996, 2004). Gardner provided the educational community with a new definition of intelligence and referred to seven kinds of intelligences, which opened a new trend to education and teaching. He maintains that intelligence is not a measurable quantity, and in 1999, he included the eighth and ninth intelligences to the set. In his opinion, all people enjoy all kinds of intelligences but with and at a varying degree and level, and in the process of learning they serve as the supplementary factor for one another. According to the fact that in multiple intelligence theory Gardner considers intrapersonal, interpersonal and verbal/linguistic intelligences as the main elements that efficient and suited managers should possess, they, along with other factors such as specialization, educational experience, etc. can be used as the appointment criteria (Kelly, 2009; Abraham, 2005).

Regarding what was stated, it appears that multiple intelligence concept can enjoy a very effective role in management and managers' strategic thinking. It is generally agreed that various intelligences play an essential role in management strategic thinking; accordingly, the present researchers were determined to scrutinize the relationship between the multiple intelligences and strategic thinking power to solidify the concept for practice (Schwartz, 1996; Robert, et al., 2009).

\section{Statement of the problem}

Today, employing and having managers with strategic thinking skills are essential parts of organizations and enterprises so that they could develop and advance. More significantly, the ministry of education in any societies plays essential role in supplying and educating human resources, so the researchers were led to wonder how it would be possible to identify such managers possessing open, all-embracing, and strategic thinking powers. The organization also tries to appoint them as the chief executive managers in organizations and enterprises so that they could go through a well-established and defined path of development and advancement. One of the biggest problems the educational system in Iran faces is the appointment of efficient and competent managers for high schools. Moreover, teachers are needed to enjoy high powers of thinking to help the system of education better develop because even making a small mistake in selecting thinkers may result in big losses (Iranzadeh et al., 2008). As known, psychology has faced various changes in recent years and the emergence of new theories into the realm of arts and management has challenged many of the traditional concepts and theories such as the concept of intelligence. Furthermore, in defining intelligence, there is a big disagreement among the psychologists. By surveying the definitions on intelligence, one can solely come to an only common point among them: the abstractness. Some psychologists consider intelligence as an individual's general and common abilities for a purposive course of action, logical thinking, and effective adaptability with the environment. Binet and Simon (1905) considered intelligence as right judgment for correct perception and reasoning (Feizabadi, 2004; Emami \& Izadi, 2008; Moridi et al., 2014; Riggio et al., 2002).

About eighty years after the development of intelligence tests, one of the Harvard University psychologists, Howard Gardner objected to intelligence measurement. In his book 'The Frameworks of Mind', Gardner (1983) distinguished at least seven major intelligences. He stated that a set of abilities and skills exists in individuals and they emerge in various forms or shapes. To explain the types of intelligence, Gardner et al. (1983) presented their theory of multiple intelligences by investigating special group individuals' cognitive abilities and complications. Gardner holds that 
individuals differ from each other in terms of their different intelligences. He continues that intelligence is a bio-cognitive gift that is affected by experience, culture, and motivating factors and that identifying and developing human beings' intelligences is of great importance. With this conceptualization and definition in mind, the following questions arise:

- Can this theory be applied to help appoint the most suited and efficient managers to the organizations, especially the system of education?

- Can one, by investigating the relationship between Gardner's new set of multiple intelligences and required skills, help managers of organizations to select the best suited individuals for different managerial positions inside the system?, and

- Can one establish a solid relationship between 'the multiple intelligences' that is managers' required skills and 'the strategic thinking skills' that is today's organizations' requirement and managers' characteristic through which one can help appoint the best suited managers for organizations?

The present study was to find out an answer for the following main question:

- Is there a significant relationship between Gardner's multiple intelligences and Maneh and Semelqan high school principals and teachers'strategic thinking skills?

\section{Significance and necessity of the study}

Many of scholars such as Mintzberg and Hamel in the field have tried to present clear-cut features of strategic thinking concept. What can be drawn from the views of the specialists in the field is that the outcome of strategic planning without the strategic thinking is merely a theoretical plan without its ending in work. On the contrary, when strategic thinking is present, one can get assured that the outcome of strategic planning is a creative and effective strategy that is in turn the most important subject matter of strategic thinking itself (Armstrong, 2003, 2009; Rigby et al., 2002).

When it comes to strategy, people mostly mull over the thing that their minds are ready to observe. Some maintain that strategic thinking is only for the individuals who are at the top and are the chief managers, but strategic thinking is something beyond that. Thinking quality improvement is required at any level and must be taken care of (Kilton, 2001:9). Strategic thinking paves the way for education, development, and innovation since on the one hand it helps managers understand their responsibilities and duties leading to creativity, and, on the other, it helps establish the necessary grounds for communication and interactions between managers and their staff leading to their understanding and enjoying their rights and creativity. Therefore, one should get access to the situation where all managers can be equipped with strategic thinking. Therefore, strategic thinkers have become necessary among the school managers, the ones that can make and find future greatly different and solve the problems and issues creatively (Ghafarian \& Aliahmadi, 2005; Azarfar, 2007).

With the significance recognized and the importance of making attempts to employ individuals with their special abilities and skills in line with the requirements and problems identified, the present researchers is decided to investigate the relationship between multiple intelligences and strategic thinking. The study tries to identify the relationship between multiple intelligences each in turn and discovers the individuals who have higher abilities of strategic thinking to achieve the goals set.

\section{Objectives of the study}

In regard with the importance of strategic thinking in this modern ever-changing world, the present study was set to scrutinize the multiple intelligences (based on Gardner's theory) and the strategic thinking variables, while identifying the relationship between them to help organizations (schools) 
appoint managers and staff equipped with such high quality skills and abilities as multiple intelligences and strategic thinking.

\subsection{The major objective}

- To identify the relationship between Howard Gardner's multiple intelligences and Maneh and Semelqan high school principals and teachers' strategic thinking

\subsection{The minor objectives}

- To identify the relationship between Maneh and Semelqan high school principals and teachers' intrapersonal intelligence and their strategic thinking

- To identify the relationship between Maneh and Semelqan high school principals and teachers' interpersonal intelligence and their strategic thinking

- To identify the relationship between Maneh and Semelqan high school principals and teachers' verbal/linguistic intelligence and their strategic thinking

\section{Background of the study}

In their study entitled 'The effect of Gardner's Multiple-intelligence-based education on the spelling mistakes of Isfahan third grade primary school students with learning disabilities', Ranjbari et al. (2013) concluded that Gardner's Multiple-intelligence-based education significantly affected the spelling mistakes of Isfahan third grade primary school students with learning disabilities. These findings were used as an intervening method to eradicate the spelling problems of the students with learning disabilities.

In another study entitled 'The study of the relationship between the multiple intelligences and Azerbaijan's commercial and industrial enterprise staff's general self-effectiveness (self-efficacy)', Hashemi et al. (2013) came to this conclusion that there was a significant relationship between multiple intelligences and staff's self-efficacy. Hoffman and Frost (2006) studied the relationship between emotional, social, and cognitive intelligence and transformational leadership dimensions and stated that the transformational leadership dimensions include leaders' appeal, mental stimulation ability, and self-attention ability. At long last, they found that there was a significant relationship between cognitive intelligence and mental stimulation ability, between social intelligence and charismatic ability, and between cognitive intelligence and self-attention ability. The study that was conducted by Fiona Greatz (2002) in Diacon University of Australia touched upon the relationship between the staff's strategic thinking and the principals' emotional intelligence. The findings showed that there was a significant and direct relationship between the two variables and it was stated that where the staff enjoyed a high strategic thinking level, the managers, too, enjoyed a high emotional intelligence (Aqajani \& Rostami, 2013; Aqazadeh, 2006)

\section{Research hypotheses}

- There is a significant relationship between Maneh and Semelqan high school principals and teachers' interpersonal intelligence and strategic thinking.

- There is a significant relationship between Maneh and Semelqan high school principals and teachers' intrapersonal intelligence and strategic thinking.

- There is a significant relationship between Maneh and Semelqan high school principals and teachers' verbal/linguistic intelligence and strategic thinking. 


\subsection{Research variables}

Each of Gardner's multiple intelligences was taken as an independent variable and the strategic thinking was treated as the dependent variable. Moreover, the educational level and the subjects' gender were moderator variables.

\subsection{Intelligence}

Intelligence is one of the issues that have long been attended by human beings and is one of the factors that can cause individuals' differences. One of the differences between individuals that lead to the emergence of individuals' unique characteristics is their intelligence differences. According to the traditional view, intelligence is the intuitional, integrated, and measurable trait (Shall, 2008).

Moreover, intelligence has been under focus since human's earliest written history, but since its being scientifically scrutinized, such cognitive elements as memory, problem solving, and thinking have been spotlighted. Today not only the non-cognitive aspects of intelligence such as emotional, personal, and social abilities are studied, but they also are implemented as predicting indexes for one's success and adaptability in life (Robert et al., 2009).

To achieve its goals, an organization needs to have intelligent and capable managers who can, by employing their multiple intelligences and by mobilizing all facilities and possibilities, lead the organizations towards the effective leadership and determined targets. In regard with the significance of intelligence, especially multiple intelligences for the managers of organizations in establishing strategic thinking, analyzing the problems and the direct and positive effects staff's performance, the necessity of getting to know this concept is more than ever before felt (Nicholson-Nelson, 1998)

Intelligence as an ability to perceive others' emotions and requirements can effectively help others reach their long and short term organizational objectives and satisfy them. Regarding the fact that intelligence is one's power and ability to use his/her own and others' emotions in individual and group behavior to gain the maximum results with the highest satisfaction, the amalgamation of management knowledge and emotional abilities in management can help gain the well-established objectives (Hashemi et al., 2013).

\subsection{Gardner's multiple intelligences}

Unlike the past psychologists who stated that intelligence was conceived the same in all contexts and did not attend what was considered as valuable in special cultures and time, Gardner presented a new concept of intelligence. According to Gardner, intelligence is the information that can get activated in a cultural environment to solve problems by generating products that are valuable in a culture. Gardner is not the first psychologist who holds that man's talents are independent of each other; rather, he is the first one who has defined intelligence thoroughly and categorized man's talents in a multiple categorization (Iranzadeh et al. 2008).

\subsection{Gardner's multiple intelligences}

\section{- Personal intelligences}

Personal intelligences include 1) intrapersonal intelligence, and 2) interpersonal intelligence. Since the development of the two intelligences is interwoven in all cultures, Gardner considers them as too closely interrelated while they are thoroughly independent. Interpersonal intelligence is the ability to understand feelings, emotions, and excitement and is the talent to distinguish and detect exclusive feelings and to apply them as an instrument to help one perceive and guide his behaviors. In its basic form, intrapersonal intelligence is one's ability to help distinguish the pleasant feelings from the unpleasant ones and to decide to get involved or to withdraw in a situation, and at its highest level 
one can identify one set of distinctive feelings and intricately symbolize them. Interpersonal intelligence deals with the relationship of one person with the other individuals. Centrally, this talent is to distinguish individuals according to their motivation, purposes, tastes, etc. (Hashemi et al., 2006)

Based on investigations, in its earliest form, interpersonal intelligence helps us deteermine and distinguish people based on their morals and individual characteristics, and in its advanced form, it helps one to know of others' purposes and desires. Knowing the multiple intelligences plays a great role in different parts of business, too.

In traditional jobs, employees could stick with the job for a long time; in fact, in this traditional view, it is maintained that the staff that are successful shall remain in their posts for good. However, it has been for fifteen years where this ideology in human resource management has been weakened or disparaged. In the unexpected environmental changes, the role of personal intelligences has been very crucial and, in fact, has proved vital. In fact, when the staffs are asked to do their jobs as they did before, we are not paying attention to their spontaneous knowledge. Today, thanks to the high flexibility of jobs and their roles, individuals should enjoy precision and up-to-date information. People who possess intrapersonal intelligence have the following skills: the ability to distinguish their weaknesses and strengths, the capability to perceive and survey themselves, the talent to know their inner feelings, desires and dreams, the aptitude to evaluate their intellectual patterns, the facility to reason and reflect on things profoundly, and the skill to understand their relationship with the others. (Haji Hussaini and Baleghizadeh, 2010:90)

\subsection{Verbal/linguistic intelligence}

Verbal/linguistic Intelligence is a part of Howard Gardner's multiple intelligence theory that deals with an individual's ability to understand both spoken and written language as well as their ability to speak and write themselves, (as cited in Wilson, 2004). Verbal/linguistic intelligence deals with the application of language. Gardner focuses on four aspects of verbal/linguistic intelligence that magnificently influence the societies, (Gardner, 1993:38-41).

The four aspects are:

- Elocution: Elocution refers to one's ability to persuade others in justifying an action

- Linguistic memory competence: This competence helps people memorize the information

- Explanation competence: This competence helps individuals learn languages and describe themselves through the language

- Competence for the explanation of activities

\subsection{Strategic competence}

Strategic thinking means creating innovative strategies that can be effective and constructive and can picture a potential panorama for the person or organization, the one that is considerably different from the present landscape (Ahmadi, 2005; Ackatcherian, 2001).

In regard with the definition presented above, it is necessary to refer to the concept of strategy as the product of strategic thinking. Each definition has looked at the subject matter from different point of view. Quinn considers strategy as a program that integrates an organization's goals. Porter states that strategy is about the composition of activities. He holds that strategy is the creation of an organization's balancing system that can make its activities fit, (Heresy et al., 2002:98). According to Porter, strategy is the process of creating unique and valuable situations for an organization (Graetz, 2002). Mintzberg $(1987,1994)$ presents five definitions for strategy: 
1. Strategy as a plan

2. Strategy as ploy

3. Strategy as a pattern

4. Strategy as a position

5. Strategy as a perspective (Ade Feo and Janssen, 2001:4)

\subsection{The concept of strategy}

Strategic thinking is an elaborate concept, but this does not imply that it is a vague concept (Bonn, 2001, 2005). The term 'strategic thinking' is used so widely in the strategic management literature today that it faces losing its meaning. Most of the people who use this term really cannot define it duly. Strategic thinking has taken up special features, but these common definitions are far away from the intended conceptualizations the developers of the concept followed (Liedtka, 1998). However, strategic thinking can successfully convey the content of strategic management. As a new attitude, strategic thinking has blown a new life to the old strategic management theory. Attempts have been made to give a meaningful picture of strategic thinking (Antonic \& Hisrich, 2003).

\subsection{Research methodology}

The method of carrying out the present study was an applied method of inferential, descriptive and correlational. The population of the study was comprised of all the high school principals and teachers (200 subjects) of Maneh and Semelqan in the educational year of 2013-2014.

\subsection{The procedures and instruments}

The instruments of collecting the data in the present study were two questionnaires of multiple intelligences (50 items) and strategic thinking (30 items).

\section{Table 1}

The Cronbach's Alpha Quotient

\begin{tabular}{lcc}
\hline Questionnaire & Number of items & Cronbach's Alpha Quotient \\
\hline Multiple intelligences & 50 & 0.893 \\
Strategic thinking & 30 & 0.944 \\
\hline
\end{tabular}

To measure the variables, the researchers used the interval scale, and to identify the type and relationship between the variables the Pearson correlation was employed. To analyze the data, the descriptive and inferential statistics -SPSS- was applied. In regard to the variables of the study, the Kolmogorov-Smirnov normal distribution test was administered and to analyze the correlation between the variables of the study the Pearson Correlation was used.

\section{The research hypothesis test}

The first hypothesis touched upon the relationship between Maneh and Semelqan high school principals and teachers' interpersonal intelligence and strategic thinking. To test it, the hypothesis was presented in two statistical hypotheses: $\mathrm{H}_{1}$ (representing the assumption) and $\mathrm{H}_{0}$ (negating the assumption).

\section{Table 2}

The results of Pearson correlation for the first hypothesis (Interpersonal intelligence)

\begin{tabular}{lcc}
\hline Variable & Factor & Strategic thinking \\
\hline \multirow{3}{*}{ The first Hypothesis } & correlation & 0.243 \\
& Level of significance & 0.000 \\
& Subjects & 127 \\
\hline
\end{tabular}

The results of Table 2 indicates the correlation between interpersonal intelligence and principals and teachers' strategic thinking which was 0.243. Considering the fact that the estimated level of 
significance equaled 0.000 and the true level was 0.95 , it could be claimed that $\mathrm{H}_{0}$ was rejected and $\mathrm{H}_{1}$ approved. Thus, it could be concluded that there was a significant relationship between Maneh and Semelqan high school principals and teachers' interpersonal intelligence and strategic thinking; that is, interpersonal intelligence had a great part in developing and promoting principals and teachers' strategic thinking, and once the interpersonal intelligence was escalated, the strategic thinking improved.

The second hypothesis touched upon the relationship between Maneh and Semelqan high school principals and teachers' intrapersonal intelligence and strategic thinking. To test it, the hypothesis was presented in two statistical hypotheses: $\mathrm{H}_{1}$ (representing the main assumption) and $\mathrm{H}_{0}$ (negating the assumption).

\section{Table 3}

The results of Pearson correlation for the second hypothesis (Interpersonal intelligence)

\begin{tabular}{lcc}
\hline Variable & & Strategic thinking \\
\hline \multirow{3}{*}{ The second Hypothesis } & correlation & 0.126 \\
& Level of significance & 0.159 \\
\hline
\end{tabular}

The results of Table 3 indicates that the correlation between intrapersonal intelligence and principals and teachers' strategic thinking was 0.126. Considering the fact that the estimated level of significance equaled 0.159 and the true level was 0.95 , it could be claimed that $\mathrm{H}_{0}$ was approved and $\mathrm{H}_{1}$ rejected. Thus, it could be concluded that there was no relationship between Maneh and Semelqan high school principals and teachers' intrapersonal intelligence and strategic thinking.

The third hypothesis touched upon the relationship between Maneh and Semelqan high school principals and teachers' verbal/linguistic intelligence and strategic thinking. To test it, the hypothesis was presented in two statistical hypotheses: $\mathrm{H}_{1}$ (representing the main assumption) and $\mathrm{H}_{0}$ (negating the assumption).

Table 4

The results of Pearson correlation for the third hypothesis (Verbal/linguistic intelligence)

\begin{tabular}{lcc}
\hline Variable & & Strategic thinking \\
\hline \multirow{2}{*}{ Hypothesis 3 } & correlation & 0.140 \\
& Level of significance & 0.117 \\
\hline
\end{tabular}

The table above indicates that the correlation between verbal/linguistic intelligence and principals and teachers' strategic thinking was 0.140 . Considering the fact that the estimated level of significance equaled 0.117 that was over 0.05 , while the true level hit 0.95 , it could be claimed that $\mathrm{H}_{0}$ was approved and $\mathrm{H}_{1}$ rejected. Thus, it could be concluded that there was no relationship between Maneh and Semelqan high school principals and teachers' verbal/linguistic intelligence and their strategic thinking power.

\section{Conclusion}

The multiple intelligence theory is an appropriate model to investigate individuals' educational promotion and advancement. Not only does the application of Howard Gardner's multiple intelligences makes individuals more creative, but it also improves the principals and teachers' learning and creativity in their in-service training which in turn improves the students' learning.Another issue which is of importance is that individuals' multiple intelligences are not fixed throughout their lives, but they can be recovered through exercise and teaching. Thus, it is suggested that organizations hold workshops and present courses proportionate to their needs and abilities and based on multiple intelligence theory so that the staff of the organization are helped to improve their intelligences and help the organization achieve their goals set. Nevertheless, even with the 
investigations conducted and with the knowledge that the relationship between multiple intelligences and strategic thinking is established, it feels essential that merely employing the individuals with high multiple intelligences related to strategic thinking does not suffice; rather, there are conditions and factors that must be attended, and at long last it is those factors that can potentially and practically help organizations, especially the educational, system foster.

\section{Practical suggestions}

- It is suggested that, with the great changes having occurred in the educational system in the third millennium, such newer variables as multiple intelligences be incorporated and considered in selecting and appointing the principals and teachers.

- It is suggested that the required grounds for the increase and reinforcement of principals and teachers' multiple intelligences and strategic thinking and the required paths to lead them towards using the strategic thinking be established.

- To identify and devise strategies to reinforce multiple intelligences at different organizational levels of schools can help them turn into a learning organization. Thus, it is suggested that practical and operational measures be taken to plan out short-term and long term goals to help achieve the goals.

- It is suggested that seminars, conferences, and workshops be held to identify and expand the concept of multiple intelligences in education.

- It is suggested that university course, teacher-education, and in-service-teacher training syllabi be based on the multiple intelligence theory by considering the principals and teachers' age, gender, learning potentials, and the type of their jobs.

- It is suggested that principals and teachers' multiple intelligence level be evaluated to help promote their vocational status based on their multiple intelligences.

- With the findings obtained from the present study, it is suggested that, for the organizations to equip themselves with the $21^{\text {st }}$-century-world's most modern state-of-the-art strategic thinking, they employ principals that have higher multiple intelligences.

\section{References}

Abraham, S. (2005). Stretching strategic thinking. Strategy \& leadership, 33(5), 5-12.

Ackatcherian, C. (2001). Mergers and Acquisitions: Why do they fail? Unpublished MBA Project Final Report, Cal Poly Pomona, May, p 34.

De Feo, J. A., \& Janssen, A. (2001). Implementing a strategy successfully. Measuring Business Excellence, 5(4), 4-6.

Ahmadi, A.A. (2005). Creative individuals in Iranian educational system. Tehran: Rasaneh Takhasosi Publications.

Ahmadi, M.H. (1991). Strategic planning and its applications. Sayeh Nam Publications. Bruce, A., \& Langdon, K. (2009). Strategic thinking. Dorling Kindersley Ltd.

Antonic, B. \& Hisrich, R. D. (2003). Clarifying the entrepreneurship concept. Journal of Small Business and Enterprise Development, 10(1), 7-24.

Aqajani, S., \& Rostami, M. (2013). To determine the building blocks of strategic thinking. Tadbir Monthly, No. 130.

Aqazadeh, H. (2006). The development of strategic thinking: a principal capacity. Tadbir, 149, 18-23. Armstrong, T. (1993). 7 kinds of smart. Gramedia Pustaka Utama.

Armstrong, T. (2009). Multiple intelligences in the classroom. Ascd.

Azarfar, F. (2007). The evaluation of multiple intelligences at home and school. Zarih Publications. Binet, A., \& Simon, T. (1905). The development of intelligence in children. San Francisco: Freeman. Bonn, I. (2001). Developing strategic thinking as a core competency. Management Decision, 39(1), 63 71. 
Bonn, I. (2005). Improving strategic thinking: a multilevel approach. Leadership \& Organization Development Journal, 26(5), 336-354.

Emami, A., \& Izadi, B. (2008). Improvement in strategic thinking: a multi- level approach. International Strategic Management Conference.

Moridi, H., Farsi, F., Yousefi, Z., \& Farsi, M. (2014). Analysis of the Relationship between Emotional Intelligence and Entrepreneurial Characteristics of Students through Structural Equation Modeling (Case Study: Students of Islamic Azad University, South Tehran Branch). Advances in Environmental Biology, 8(9).

Gardner, H. (1985). Frames of mind: The theory of multiple intelligences. Basic books.

Gardner, H. (1996). Intelligence Reframed: Multiple Intelligences for $21^{\text {st }}$ century. New

York: Basic Books.

Gardner, H. (2004). Changing minds: The art and science of changing our own and other people's minds. Harvard Business Press.

Ghafarian, V. (2005). Five commands for strategic thinking. Tehran: Nashr-e-farda.

Graetz, F. (2002). Strategic thinking versus strategic planning: towards understanding the complementarities. Management decision, 40(5), 456-462.

Henden, G. (2004). Intuition and its role in strategic thinking (Doctoral dissertation, Norwegian School of management).

Hashemi, V., Bahrami, H., Karimi, M.H. (2013). The study of the relationship between Gardner's multiple intelligences and students' educational progress. Journal of Psychology, 39(3).

Heresy, P., Blanchard, K. H., \& Johnson, D. E. (2002). Management of Organizational Behavior,'.

Hoffman, B. J., \& Frost, B. C. (2006). Multiple intelligences of transformational leaders: An empirical examination. International Journal of Manpower, 27(1), 37-51.

Iranzadeh, S., Sabahi, E., \& Amari, H. (2008). The strategic thinking. Tabriz: Forouzesh Publications.

Kelly, T. (2009). A study of the teaching and learning of mathematics through multiple

intelligences and differentiated instruction with selected third grade teachers. Doctoral Dissertation, Union Institute and University, USA.

Lebhar-Friedman, Inc. (2003). Recruiting execs multiple intelligence learning. Journal of Nation's Restaurant News, 37(27).

Liedtka, J. M. (1998). Linking strategic thinking with strategic planning. Strategy and leadership, 26(4), 30-35.

Porter, M. E. (1996). What is strategy?. Published November.

Mintzberg, H. (Ed.). (2003). The strategy process: concepts, contexts, cases. Pearson Education.

Mintzberg, H. (1987). The strategy concept 1: five p's for strategy. U. of California.

Mintzberg, H. (1994). Rise and fall of strategic planning. Simon and Schuster.

Nicholson-Nelson, K. (1998). Developing students' multiple intelligences. J. Moss (Ed.). New York: Scholastic Professional Books.

Nikkho, M., Rahmani, M.H. (2013). The types of intelligences with a focus on spiritual intelligence. Azad Islamic University of Mashhad.

Nolen, J. L. (2007). Multiple intelligences in the classroom. Education journal, 5124(1), 115-119.

Rigby, D. K., Christensen, C. M., \& Johnson, M. (2002). Foundations for growth: How to identify and build disruptive new businesses. MIT Sloan Management Review, 43(3), 22-32.

Riggio, R. E., Murphy, S. E. \& Pirozzolo, F. (2002). Multiple intelligences and leadership. Mahwah, NJ: Lawrence Erlbaum Associates, Inc.

Robert, W. et al. (2009). Giftedness in intrapersonal-intelligence. Western Reserve University, Department of Psychology. University of London (UCL) AI, Mach. Learning, Evolve Computing

Schwartz, P. (1996). The Art of the long view: Planning for the Future in an uncertain world. New York: Currency Doubleday, 241-248.

Shall, A. C (2008). A study of the relationship between multiple-intelligences and achievement as measured by Delaware student testing program (DSTP) scores in reading, mathematics, and writing. Doctoral Dissertation, Wilmington College, Delaware, USA

Wilson, I. (1994). Strategic planning isn't dead-it changed. Long range planning, 27(4), 12-24. 